Journal of Advanced Research in Fluid Mechanics and Thermal Sciences

Journal homepage: www.akademiabaru.com/arfmts.html ISSN: 2289-7879

\title{
Rheological Behaviour of Purified Banana Peel Pectin from 'Saba' Banana [Musa BBB saba (Musa acuminata x Musa balbisiana)] Peel Applied to Beverage
}

\author{
Joel Padilla Rivadeneira ${ }^{1,2,}{ }^{*}$, Tao $\mathrm{Wu}^{2}$, Prince Joseph Valencia Gaban ${ }^{1}$, Katherine Ann Tamolang \\ Castillo-Israel $^{1}$ \\ 1 Institute of Food Science and Technology, College of Agriculture and Food Science, University of the Philippines Los Baños, College, Laguna, \\ 4031, Philippines \\ 2 Department of Food Science, The University of Tennessee, Knoxville, 2510, River Drive, Knoxville, Tennessee, 37996, USA
}

ARTICLE INFO $\quad$ ABSTRACT

\section{Article history:}

Received 21 December 2019

Received in revised form 3 April 2020

Accepted 5 April 2020

Available online 30 June 2020

\begin{abstract}
The crude pectin from 'saba' banana peel was purified through ultrasound-assisted dissolution in dilute acid, reprecipitation by ethanol, and freeze-drying. The purity of the resulting pectin (BPP), in terms of the total pectic content, increased from 17.25 to 46.77\%. BPP was applied to different fluids: whey protein isolate (WPI) solution and orange juice to test its thickening property, and to soybean oil to test its emulsifying properties. The viscosity profile showed that the formed WPI/BPP complex exhibited a shear-thinning property. The highest viscosity was also achieved at $[\mathrm{WPI}] /[\mathrm{BPP}]=5$ and $\mathrm{pH}$ 5. For the effect of pectin on the in vitro digestion viscosity of orange juice, results showed that BPP increased the thickness of the fluid both in the gastric and intestinal levels, thus, potentially increasing the satiety value of the orange juice. For the emulsifying property, BPP and commercial pectin were most effective at $40 \%$ and $50 \%$ oil content, with the earlier producing smaller emulsion droplets and a more stable emulsion.
\end{abstract}

Keywords:

\section{Introduction}

Banana is one of the most important crops in the Philippines. It is a locally grown fruit that is available in the market year-round. Aside from being utilized locally, banana fruits are exported to other countries. Food and Agriculture Organization of the United Nations (FAO) [1] reported that the Philippines is the second-largest exporter of banana fruits in the world, accounting for a $13 \%$ share of the total global shipment. In 2018, the Philippines was able to produce around 9.35 million metric tons comprised the majority of Cavendish and 'saba' variety [2-5]. Banana fruits are usually consumed fresh in their ripened state but are also processed to provide a wide range of food products. Some of

\footnotetext{
* Corresponding author.

E-mail address: jprivadeneira@up.edu.ph (Joel Padilla Rivadeneira)
} 
the processed foods from banana include flour, chips, ketchup, and sweetened products. The waste generated in the processing of banana fruit is mostly peel, which is around two-thirds of the fresh material in terms of weight. Since there is a high volume of banana production and processing activities, high production of waste may be assumed. These wastes, especially banana peel, contain high-value compounds with potential applications in food, pharmaceutical, cosmetics, flavors, and fragrances [6]. The utilization of banana peel to produce high-value products could add value to the fruit itself and, ultimately, help the banana industry in the country.

Pectin, a high-value food ingredient, is present in the banana peel. It is a complex heteropolysaccharide with a backbone made from $\alpha-1,4$-galacturonic acid residues that are partially esterified with methyl alcohol or acetic acid at the carboxylic acid. It comprises $8-14 \%$ of the cell wall [7], and like most of the polysaccharide in plants, it is considered to be both polymolecular and polydiverse. In fruit peels, pectin is found in the middle lamellae and primary cell wall together with cellulose and hemicellulose. At least 300 galacturonic acid units linked by $\alpha-1,4$ glycosidic linkages make up pectin [8].

Pectin is generally used in the food industry as a gelling agent in fruit applications. It also acts as stabilizers for emulsions, sauces, juices, dairy, and frozen products. The market for pectin on the global scale is estimated to account for a value of USD 1.0 billion in 2019. It is expected to reach USD 1.9 billion by 2025 due to the increasing demand for natural and organic products [9]. In the Philippines, data from the Department of Trade and Industry showed that about 95,000 kilograms were imported in 2011, valued at around \$52.4 million [10]. While there have been no recent data on pectin importation, the global projection on its demand can indicate that pectin production from different potential raw materials is a good direction for research

In this study, crude pectin extracted from 'saba' banana [Musa BBB 'saba' (Musa acuminata $x$ Musa balbisiana)] peel using the protocol described by Castillo-Israel [11] was further purified to widen its potential for food application. As a thickening agent, this study explored the potential of the purified banana peel pectin (BPP) in enhancing the viscosity of some beverages. An improvement of this sensory attribute could increase consumer satisfaction translatable to increased sales and revenue. In addition, Zhu et al., [12] suggest that the intake of viscous food results in a slower eating rate and increases the level of fullness. Thus, viscous food products may also be catered to healthconscious individuals. The study also looked into the effectiveness of BPP as an emulsifier in a soybean oil-water mixture. A stable emulsion, if achieved, would make it easier for soybean oil to be incorporated in food products. Soybean oil is an excellent choice for study as it meets the human requirement for essential fatty acid [13]. Overall, the results of this study would promote the use of waste material as an alternative source of important food ingredients in product development and innovation.

\section{Methodology}

\subsection{Materials}

The banana peel was sourced out from a banana chips manufacturing plant in Lipa, Batangas. Chemicals used were analytical reagent-grade purchased from either Sigma Aldrich (USA) or Fisher Scientific (USA). 


\subsection{Extraction and Purification}

Crude pectin was produced following the protocol described by Castillo-Israel [14]. One percent $(\mathrm{w} / \mathrm{v})$ of the dried banana peel was soaked in $0.5 \mathrm{~N} \mathrm{HCl}(\mathrm{pH} 1.5)$ at $90^{\circ} \mathrm{C}$ for 4 hours. The mixture was then cooled and filtered through a screen with 1-mm mesh size and two-layer cheesecloth. The filtrate was collected and then added with twice its volume of absolute ethanol. The resulting precipitate (crude pectin) was filtered through a Miracloth, then oven-dried for 2 days at $55^{\circ} \mathrm{C}$.

Ten percent $(\mathrm{w} / \mathrm{v})$ of the crude pectin was dispersed in a hydrochloric acid solution $(\mathrm{pH} 3)$. The mixture was then subjected to an ultrasonication (Sonics and Materials VC-750, USA, 0.5 in. probe) at a $60 \%$ pressure amplitude for two minutes in a cold-water bath, then to centrifugation at 15,000 $x \mathrm{~g}$ for 15 minutes. The mixture was filtered using Miracloth. An equal volume of $100 \%$ ethanol was added to the filtrate to precipitate the pectin. Another round of centrifugation and filtration was performed, and the resulting purified banana peel pectin (BPP) was freeze-dried and stored at room temperature.

\subsection{Characterization}

BPP was characterized for its equivalent weight and methoxyl content following Rangana's method [15], and total pectic content adapted by Blumenkrantz et al., [16]. For the equivalent weight determination, a $0.5 \mathrm{~g}$ sample was transferred to a $250-\mathrm{mL}$ conical flask containing $5 \mathrm{~mL}$ of $95 \%$ ethanol. The mixture was mixed. One gram of $\mathrm{NaCl}, 100 \mathrm{~mL}$ of deionized $\mathrm{H}_{2} \mathrm{O}$, and six drops of phenol red were added to the mixture. It was titrated against $0.1 \mathrm{~N} \mathrm{NaOH}$ until the purple endpoint. Equivalent weight was calculated using the formula

Equivalent weight $=\frac{\text { weight of sample }(g)}{\text { volume of } \mathrm{NaOH}(\mathrm{mL}) \times \text { concentration of } \mathrm{NaOH}(N)} \times 1000$

To the neutral solution titrated for equivalent weight containing $0.5 \mathrm{~g}$ of pectic substance, $25 \mathrm{~mL}$ of $0.25 \mathrm{~N} \mathrm{NaOH}$ was added. The solution was shaken thoroughly and was allowed to stand for 30 minutes at room temperature in a flask with a stopper. A $25 \mathrm{~mL}$ portion of $0.25 \mathrm{~N} \mathrm{HCl}$ was added, and the resulting solution was titrated with $0.1 \mathrm{~N} \mathrm{NaOH}$ to the purple endpoint. The $\mathrm{MeC}$ was calculated using the formula

$\operatorname{MeC}(\%)=\frac{\mathrm{mL} \text { alkali } \times \mathrm{N} \text { alkali } \times 3.1}{\text { weight of sample, } \mathrm{g}}$

Factor 3.1 is the converted equivalent weight of the methoxyl group multiplied by 100.

For the total pectic content, $7.5 \mathrm{mg}$ of the sample was placed in a test tube containing a magnetic stir bar. The sample was placed in an ice bath, added with $5 \mathrm{~mL}$ cold $\mathrm{H}_{2} \mathrm{SO}_{4}$, and then stirred to allow the complete dissolution of the material. A total of $1.25 \mathrm{~mL}$ of deionized water was slowly added, followed by continuous stirring for 5 minutes. Another $1.25 \mathrm{~mL}$ of deionized $\mathrm{H}_{2} \mathrm{O}$ was added, followed by constant stirring for 5 minutes. Upon complete digestion, the sample was then filtered using a $0.45 \mu \mathrm{m}$ syringe filter. The filtered sample was diluted to $1: 10$. One milliliter of the diluted sample was drawn out and transferred to a test tube in an ice bath. Six milliliters of cold $\mathrm{H}_{2} \mathrm{SO}_{4} /$ sodium tetraborate ( $4.77 \mathrm{~g}$ sodium tetraborate in $1 \mathrm{~L}$ of $\mathrm{H}_{2} \mathrm{SO}_{4}$ ) was added to the sample. It was mixed thoroughly and kept cool. Tubes were boiled for 5 minutes at $100^{\circ} \mathrm{C}$ and then placed immediately in an ice bath. One-tenth milliliters of $0.0125 \mathrm{M}$ m-hydroxydiphenyl $(0.15 \%$ in $0.5 \% \mathrm{NaOH}$ - stored at $4^{\circ} \mathrm{C}$ in a container wrapped with aluminum foil) was added. The sample was repeatedly mixed in a 
vortex until it reached room temperature. The absorbance of the sample was read at $520 \mathrm{~nm}$ against a blank after 20 minutes. For the standard, 0 to $100 \mu \mathrm{g} / \mathrm{mL}$ of galacturonic acid in deionized $\mathrm{H}_{2} \mathrm{O}$ was used. For blank, $0.1 \mathrm{~mL}$ of $0.5 \% \mathrm{NaOH}$, instead of $\mathrm{m}$-hydroxydiphenyl, was added. The concentration of the total pectic substance, in terms of galacturonic acid, was derived from the standard curve.

\subsection{Thickening Property}

Stock solutions of whey protein isolate (WPI) $(15 \% \mathrm{w} / \mathrm{v})$ and BPP $(4 \% \mathrm{w} / \mathrm{v})$ were prepared. WPI was mixed with BPP such that the final ratios (a) of the concentration of WPI to BPP were 5,10 , and 15. The final $\mathrm{pH}$ of the mixtures was adjusted to $\mathrm{pH} 5$ using $0.1 \mathrm{M} \mathrm{NaOH}$. Mixtures were homogenized with a dispenser (IKA T18 homogenizer, Germany) at 10,000 rpm for 2 minutes then stored at $10^{\circ} \mathrm{C}$ for 24 hours.

Another set of the mixture ( $a=5)$ was prepared. It was adjusted to $\mathrm{pH} \mathrm{4,} \mathrm{5,} \mathrm{and} 6$ using $0.1 \mathrm{M}$ $\mathrm{NaOH}$ and then homogenized and stored following the same conditions as the previous set. Commercial pectin was also used as a reference.

The resulting solution was carefully transferred to the lower plate of the rheometer, and the surplus was removed using a plastic spatula after lowering the head of the rheometer to the trim position. Viscosity testing at varied shear rates $\left(2\right.$ to $\left.200 \mathrm{~s}^{-1}\right)$ was performed at $25^{\circ} \mathrm{C}$. Viscosity profile of the mixtures was measured from 2 to $200 \mathrm{~s}^{-1}$ at $25^{\circ} \mathrm{C}$.

\subsection{In Vitro Digestion Viscosity}

An in vitro digestion of a $2 \%(\mathrm{w} / \mathrm{v})$ of BPP in a commercial Simply ${ }^{\circledR}$ orange juice was performed following the protocol described by Logan et al., [17] with slight modifications. Fifteen grams of the solution was transferred to a 125-mL Erlenmeyer flask with $4 \times 1-\mathrm{cm}$ glass beads. Seven milliliters of simulated gastric fluid (SGF: $0.2 \% \mathrm{NaCl}(\mathrm{w} / \mathrm{w})$ in $0.7 \% \mathrm{HCl}(\mathrm{w} / \mathrm{v})$ ) was added. SGF also contains pepsin such that the latter's final concentration was $3.2 \mathrm{mg} / \mathrm{mL}$. The final solution was adjusted to $\mathrm{pH} 2.0$ using 0.1 to $0.5 \mathrm{M} \mathrm{HCl}$ and then incubated in a shaking water bath at $37^{\circ} \mathrm{C}$, at a speed of $175 \mathrm{rpm}$, for 2 hours, to imitate gastric digestion. The viscosity at physiological shear rates $\left(10 \mathrm{~s}^{-1}\right.$ and $\left.50 \mathrm{~s}^{-1}\right)$ was measured before incubation and after 1 and 2 hours.

To the solution used in gastric digestion, $2 \mathrm{~mL}$ of $750 \mathrm{mM} \mathrm{CaCl}$, $4.6 \mathrm{~mL}$ of simulated bile fluid (SBF: containing $8 \mathrm{mg} / \mathrm{mL}$ bile salts), and $12 \mathrm{~mL}$ of simulated intestinal fluid (SIF: $5 \mathrm{mg} / \mathrm{mL}$ pancreatin dissolved in $0.5 \mathrm{M}$ sodium phosphate buffer; $\mathrm{pH}$ 7.8) were added. The incubation with shaking was continued for 2 hours. The viscosity at physiological shear rates $\left(10 \mathrm{~s}^{-1}\right.$ and $\left.50 \mathrm{~s}^{-1}\right)$ was measured after 1 and 2 hours. Aside from the BPP, the effect of commercial pectin was also evaluated.

\subsection{Emulsifying Property}

A stock solution of $2 \%(\mathrm{w} / \mathrm{v}) \mathrm{BPP}$ in $0.02 \mathrm{M} \mathrm{NaCl}$ solution with a final $\mathrm{pH}$ of 6 was prepared. An appropriate volume of this solution was added to soybean oil such that the final mixture contained $30 \%, 40 \%$, and $50 \%$ oil. The prepared mixtures were homogenized with a dispenser (Kinematica, Polytron 10-35 GT, Luzern, Switzerland) at 10,000 rpm for 2 minutes, and then subjected to ultrasonication (Sonics, VibraCell ${ }^{\mathrm{TM}}$, Newton, Connecticut) at a $40 \%$ pressure amplitude for one minute. The final emulsion was stored at $10^{\circ} \mathrm{C}$ for 24 hours to facilitate stabilization. The index of the stabilized emulsion was measured using

Cream Index $=\frac{\text { thickness of the cream layer }}{\text { thickness of the whole sample }}$ 
The stabilized emulsion was also viewed under a 40x magnification of the polarized microscope (Olympus $^{\circledR}$, BX51, Tokyo, Japan) with a built-in digital camera (Olympus ${ }^{\circledR}$, DP70, Tokyo, Japan).

\section{Results}

\subsection{Characteristics of the Purified Banana Peel Pectin}

The methoxyl content refers to the methyl ester group attached to the galacturonic acid chain. Depending on the degree of its presence, pectin may be classified as low-methoxy or high-methoxy pectin. In this study, the methoxyl content of both acid-extracted BPP and BPP are within the typical 0.5-7\% values for low-methoxy pectin [18]. Pectin from other banana varieties, however, are highmethoxy in nature [19]. To further validate the observed property (data not shown), their gel formation was tested in an alkaline solution with calcium salt, a condition suitable for low-methoxy pectin [20]. Both pectins formed a gel, hence, a positive result (Table 1).

The total pectic content is the number of galacturonic acid units in the material. It dictates the level of purity of the pectin, which in this study, has significantly increased by $170 \%$ upon innovation in the purification method.

$\begin{aligned} & \text { Table } 1 \\
& \text { Characteristics of acid-extracted banana peel pectin (BPP) }\end{aligned}$
\begin{tabular}{lll}
\hline & Crude & Purified \\
\hline Methoxyl Content, \% & $5.25 \pm 0.0$ & $0.10+0.0$ \\
Total Pectic Content, \% & $17.25+0.4$ & $46.77+0.7$ \\
Equivalent Weight (approx.), g/eq & 1,500 & 900 \\
\hline
\end{tabular}

\subsection{Viscosity of Protein-Pectin Mixture}

The WPI solution (control) exhibited a shear-thinning property or a decrease in viscosity in response to increased shear rates. As shown in Figure 1, the addition of pectin, regardless of the mixing ratio (a), further increased WPI's viscosity while maintaining the latter's shear thinning property. This is due to the complex formed by WPI and BPP in all pH conditions used. This finding is similar to that of other carbohydrates such as guar gum [21], carboxymethyl cellulose [22], and xanthan gum [23]. It was also observed that for both types of pectin, the most viscous mixture was the one with the highest pectin concentration $(a=5)$. Between BPP and commercial pectin, the latter resulted in a more viscous mixture, which can be attributed to the latter's higher purity (around $47 \%$ ).

At $\mathrm{pH} \mathrm{4}$, an aggregation of precipitate was observed, and a suspension instead of a solution was formed. The electrostatic interaction between the positively charged protein and the negatively charged pectin was very high at this condition; hence, the formation of the precipitate [24]. The aggregation of the precipitate may be attributed to the charge neutralization of the complex [25]. The viscosity was low at this $\mathrm{pH}$ because the aggregates formed a separate phase at the bottom part of the mixture. At $\mathrm{pH} \mathrm{5,} \mathrm{the} \mathrm{interaction} \mathrm{between} \mathrm{the} \mathrm{oppositely} \mathrm{charged} \mathrm{molecules} \mathrm{was} \mathrm{still} \mathrm{present,}$ but this time, a colloidal complex was formed. This resulted in a higher viscosity of the mixture. At $\mathrm{pH} 6$, both the protein and the pectin were negatively charged. This incompatibility due to repulsion of charges prevented the assembly of a complex, resulting in two soluble co-solutes with low final viscosity [26]. The formation of the complex at $\mathrm{pH} 4$ and 5 suggests that BPP could be a potential material for hierarchical structures and delivery systems. In food application, despite performing inferior relative to the commercial pectin, results suggest that BPP can improve the texture or viscosity of a protein beverage at an appropriate $\mathrm{pH}$ (Figure 2). 


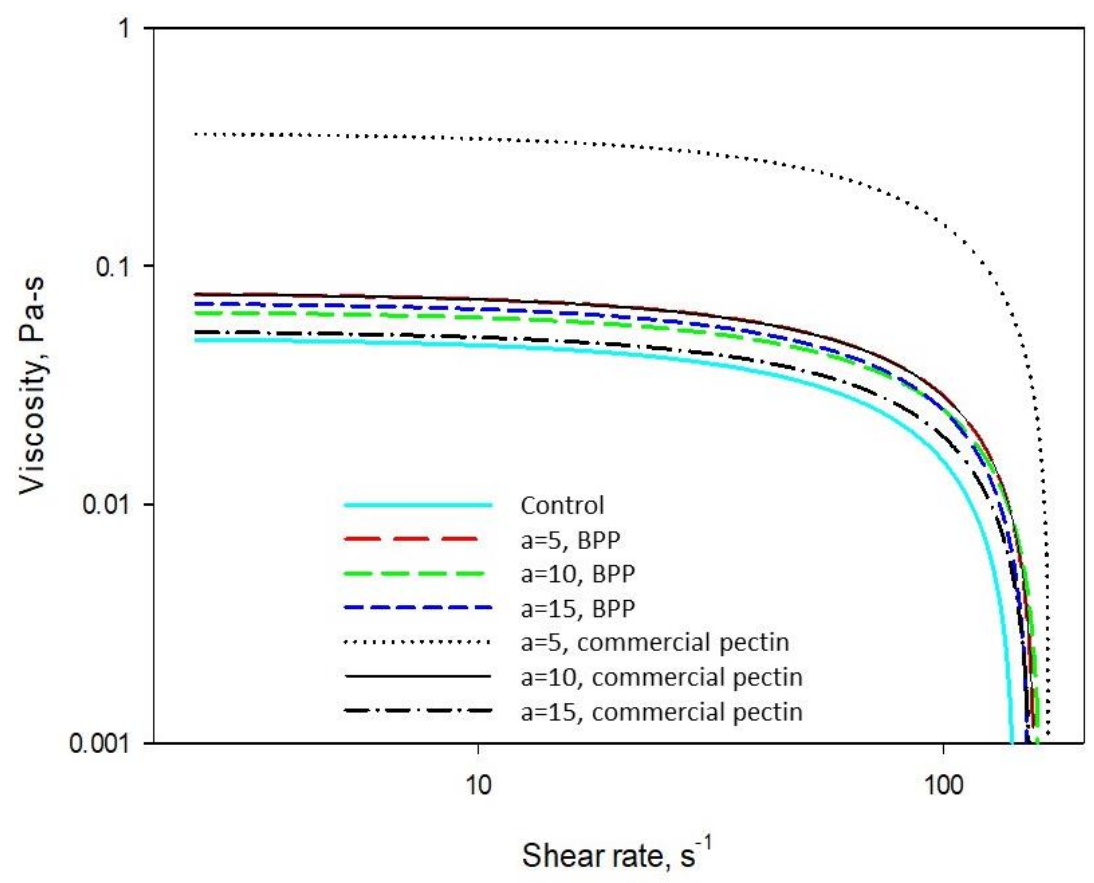

Fig. 1. Effect of mixing ratio (a) on the viscosity of the protein-pectin complex (pH 5) at $25^{\circ} \mathrm{C}(\mathrm{a}=[\mathrm{WPI}] /[$ pectin $])$

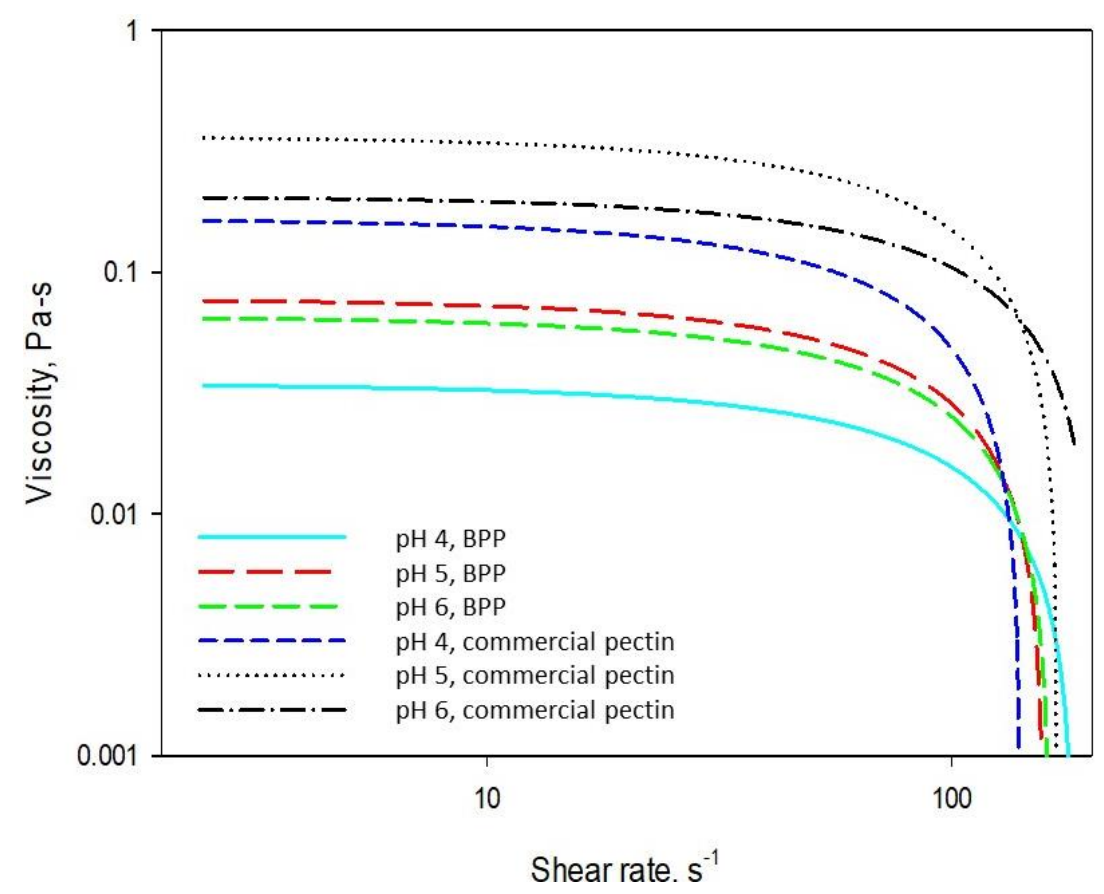

Fig. 2. Effect of $\mathrm{pH}$ on the viscosity of the WPI/BPP complex $(a=5)$ at $25^{\circ} \mathrm{C} .(\mathrm{a}=[\mathrm{WPI}] /[$ pectin $])$

In a related study involving the use of pectin extracted from Nam Wa banana (Musa (ABB group) 'Kluai Nam Wa') as a thickener [27], the use of $2.5 \%$ pectin resulted in a viscosity ranging from 8 to $15 \mathrm{mPa}$-s. This is relatively lower than the viscosity obtained using this study's BPP. It should be noted, though, that different solutions were used in the two studies. This study used a protein solution while the other used deionized water; hence, a comparison is not relevant. Nevertheless, both types of pectin increased the viscosities of their respective controls. 


\subsection{In Vitro Digestion Viscosity of Orange Juice}

Similar to the effect on the WPI solution, BPP increased the initial apparent viscosity of orange juice. During the first hour of gastric digestion, both at $10 \mathrm{~s}^{-1}$ and $50 \mathrm{~s}^{-1}$ shear rates, orange juice with pectin exhibited higher viscosity than the control. In the second hour, the same trend was observed at the $10 \mathrm{~s}^{-1}$ shear rate. However, at $50 \mathrm{~s}^{-1}$ shear rate, orange juice with BPP exhibited similar viscosity as the control. Only the commercial pectin was able to maintain the viscous property at the high levels of shear rates. In the intestinal digestion, the viscosity was higher for orange juice with BPP and commercial pectin at $10 \mathrm{~s}^{-1}$ shear rates. However, increasing the shear rate to $50 \mathrm{~s}^{-1}$ produced fluids with significantly equivalent viscosities.

In general, the whole digestion process reduced the viscosity of orange juice with and without pectin (Figure 3). This finding is in agreement with the results of a related study [28] wherein other commercial brands of pectin were used. It must be noted, though, that during digestion at a low physiological shear rate, the addition of pectin has improved the thickness of orange juice. A study correlating viscosity of food with satiety suggested that fullness during a meal is higher for highly viscous food [29]. Hence, aside from the improvement of the texture of the juice, the addition of BPP or commercial pectin could possibly increase the level of fullness during meals. For health-conscious individuals, this could be a potential diet option in maintaining healthy body weight.
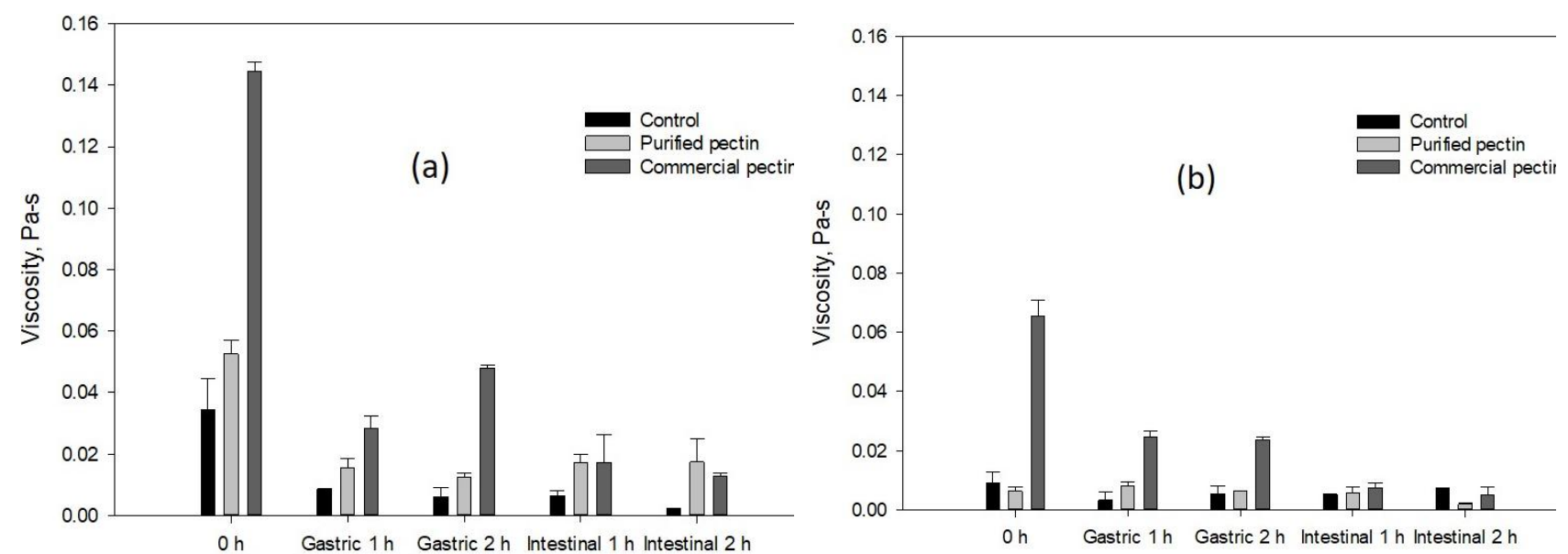

Fig. 3. In vitro digestion viscosity of orange juice with $2 \%$ pectin at (a) $10 \mathrm{~s}^{-1}$ and (b) $50 \mathrm{~s}^{-1}$ shear rates

\subsection{Emulsifying Property of Pectin}

As seen in Figure 4, both pectins were able to form soybean oil-water emulsion, as shown by the cream layer between the two components. The corresponding emulsion indices (Figure 5) showed that a higher volume of the emulsion was formed by the commercial pectin at a $30 \%$ oil ratio. Meanwhile, at $40 \%$ and $50 \%$ oil ratio, there was no significant difference $(p<0.05)$ on the emulsifying ability if BPP and commercial pectin. Thus, BPP is comparable to commercial pectin at higher oil ratios. 


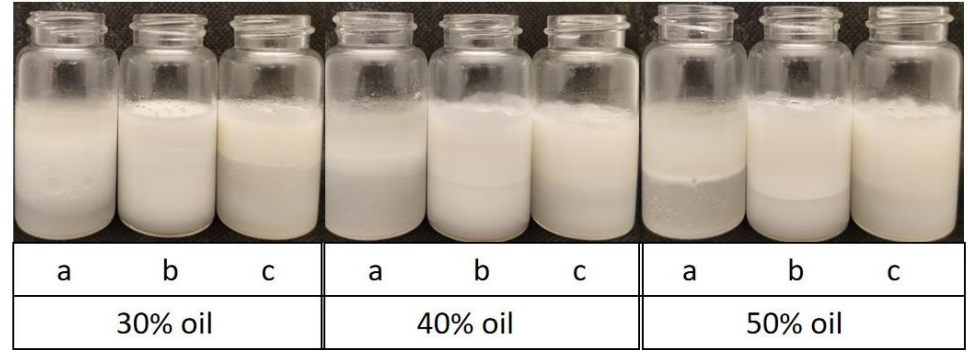

Fig. 4. Phase separation of soybean oil-water emulsion at $\mathrm{pH}$ 6 ( $a=0 \%$ BPP; $b=2 \%$ BPP; $c=2 \%$ commercial pectin)

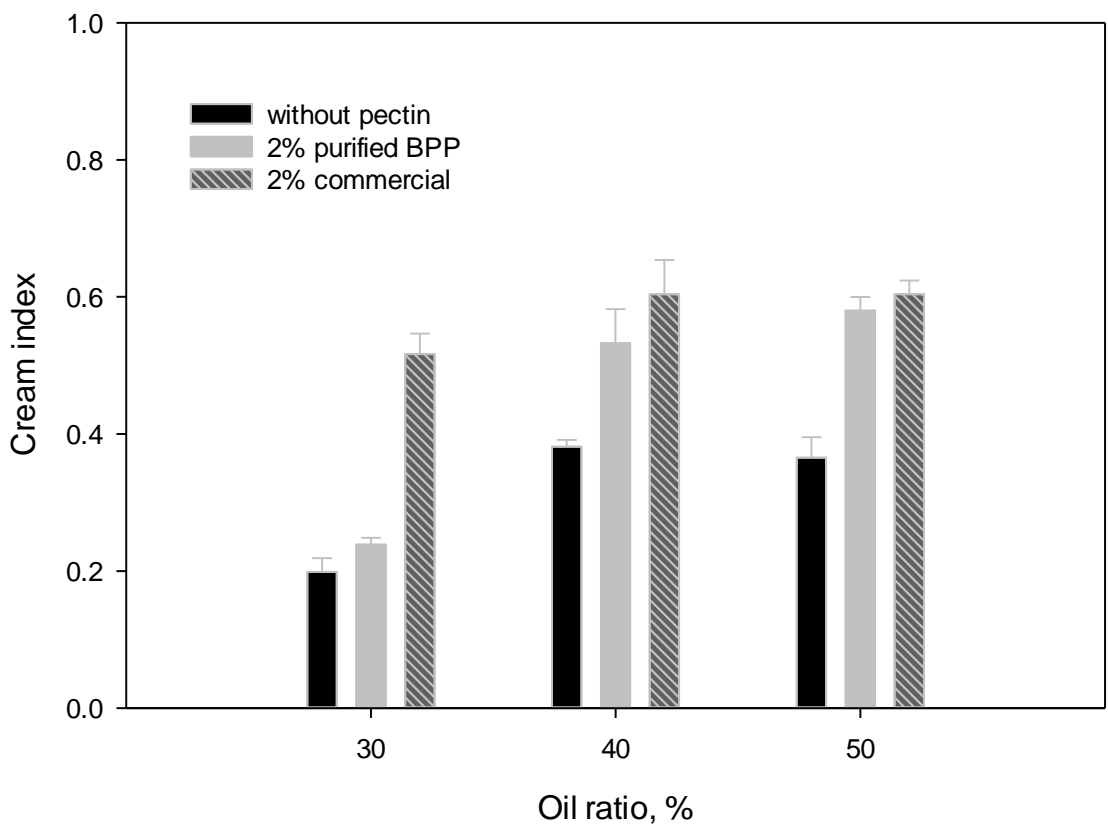

Fig. 5. Cream index at various oil ratio

While the commercial pectin showed higher emulsifying ability than BPP at $30 \%$ oil ratio, the microscopic appearance (Figure 6) showed that the BPP formed a more stable emulsion. The formation of smaller droplets by BPP suggests that the interfacial attraction between its oil droplets is stronger than that of commercial pectin. With its ability to promote emulsion stability, BPP can be a good emulsifier and stabilizer for applications such as in the pharmaceutical and food industry. In the pharmaceutical industry, emulsions are used to encapsulate lipophilic drugs for increased bioavailability [30]. Similarly, for the food industry, a stable emulsion can be used to encapsulate lipophilic functional food [31,32].

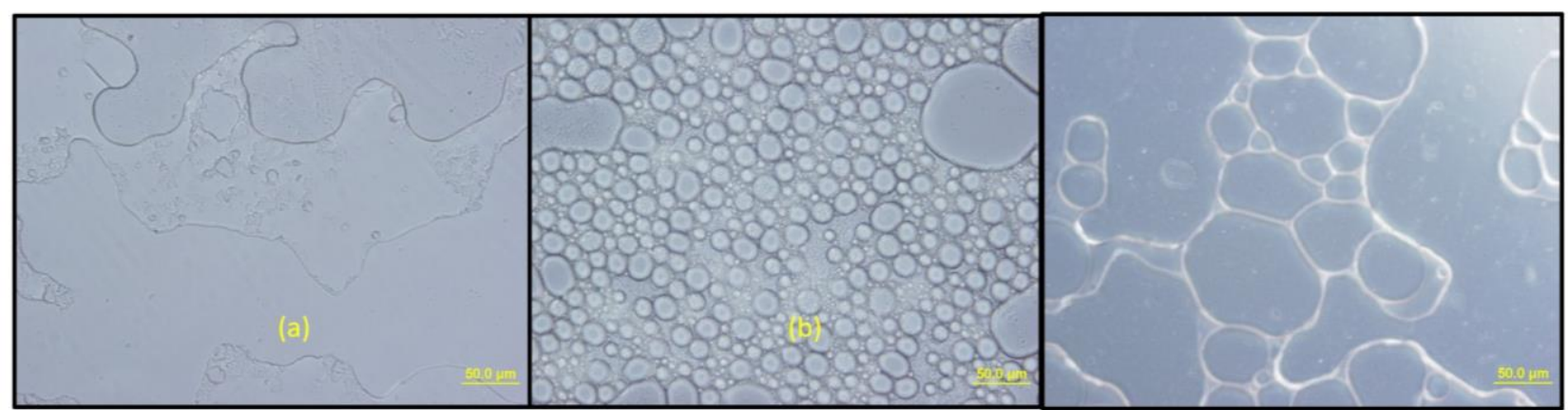

Fig. 6. Microscopy of $30 \%$ soybean oil-water emulsion at $\mathrm{pH} 6(\mathrm{a}=$ control; $b=w / 2 \%$ BPP; $c=w / 2 \%$ commercial pectin) 


\section{Conclusions}

The mixture of whey protein isolate (WPI) and purified banana peel pectin (BPP) exhibited a shear-thinning property, regardless of the mixing ratio. The apparent viscosity of the mixture also exhibited a direct relationship with the added amount of pectin. On the effect of in vitro digestion on the viscosity of orange juice with and without pectin, a decrease in viscosity relative to the initial apparent viscosity was observed. At certain points of digestion, especially in the gastric phase, where the feeling of fullness during a meal occurs, the presence of pectin resulted in a higher viscosity of the orange juice. For the emulsifying effect, there was no significant $(p<0.05)$ difference in the cream index of emulsion formed by BPP and commercial pectin. However, BPP produced smaller droplets; hence, a more stable emulsion.

\section{Acknowledgment}

The author greatly acknowledges the National Research Council of the Philippines, Accelerated Science and Technology Human Resource Development Program of the Department of Science and Technology, Philippines, and the University of Tennessee Cultural Exchange Program for technical and financial support.

\section{References}

[1] "Banana market review: preliminary results for 2018." Food and Agriculture Organization, 2018.

[2] "Major fruit crops quarterly bulletin for 2018. Volume 12. no. 1 (2018)." Philippine Statistics Authority, 2018.

[3] "Major fruit crops quarterly bulletin for 2018. Volume 12. no. 2 (2018)." Philippine Statistics Authority, 2018.

[4] "Major fruit crops quarterly bulletin for 2018. Volume 12. no. 3 (2018)." Philippine Statistics Authority, 2018.

[5] "Major fruit crops quarterly bulletin for 2018. Volume 12. no. 4 (2018)." Philippine Statistics Authority, 2018.

[6] K. A. Mohamad Said, Z. Radzib, I. Yakub and M. A. Mohamed Amin. "Extraction and quantitative determination of ascorbic acid from banana peel Musa acunimata 'Kepok'." Journal of Advanced Research in Materials Science 9, no. 1 (2015): 22-30.

[7] Taylor, Steve. The chemistry and technology of pectin. Academic Press, 2012.

[8] Akash, M.S.H., K. Rehman, and S. Chen. "Natural and Synthetic Polymers as Drug Carriers for Delivery of Therapeutic Proteins." Polymer Reviews 55, no. 3 (2015): 371-406. https://doi.org/10.1080/15583724.2014.995806

[9] "Pectin Market by Type (HM Pectin, LM Pectin), Raw Material (Citrus fruits, Apples, Sugar beet), Function, Application (Food \& beverages, Pharmaceutical \& Personal Care Products, Industrial Applications), and Region Global Forecast to 2025." Markets and Markets, 2019.

[10] "Pectin extraction process headed for commercialization." Department of Science and Technology-Philippine Council for Agriculture, Aquatic and Natural Resources Research and Development.

[11] Castillo-Israel, K. A. T., S. F. Baguio, M. D. B. Diasanta, R. C. M. Lizardo, E. I. Dizon, and M. I. F. Mejico. "Extraction and characterization of pectin from Saba banana [Musa'saba'(Musa acuminata x Musa balbisiana)] peel wastes: A preliminary study." International Food Research Journal 22, no. 1 (2015): 202-207.

[12] Zhu, Yong, Walter H. Hsu, and James H. Hollis. "The impact of food viscosity on eating rate, subjective appetite, glycemic response and gastric emptying rate." PLoS One 8, no. 6 (2013): 1-6. https://doi.org/10.1371/journal.pone.0067482

[13] Fan, Liuping, and NA Michael Eskin. "The use of antioxidants in the preservation of edible oils." In Handbook of Antioxidants for Food Preservation, pp. 373-388. Woodhead Publishing, 2015. https://doi.org/10.1016/B978-1-78242-089-7.00015-4

[14] Castillo-Israel, K. A. T., S. F. Baguio, M. D. B. Diasanta, R. C. M. Lizardo, E. I. Dizon, and M. I. F. Mejico. "Extraction and characterization of pectin from Saba banana [Musa'saba'(Musa acuminata $x$ Musa balbisiana)] peel wastes: A preliminary study." International Food Research Journal 22, no. 1 (2015): 202-207.

[15] Ranganna, Shamanna. Handbook of analysis and quality control for fruit and vegetable products. Tata McGraw-Hill Education, 1986.

[16] Blumenkrantz, N.,and Asboe-Hansen, G. "New method for quantitative determination of uronic acids." Analytical Biochemistry 54 (1973): 484-489.

https://doi.org/10.1016/0003-2697(73)90377-1 
[17] Logan, Kirstyn, Amanda J. Wright, and H. Douglas Goff. "Correlating the structure and in vitro digestion viscosities of different pectin fibers to in vivo human satiety." Food \& function 6, no. 1 (2015): 62-70.

https://doi.org/10.1039/C4FO00543K

[18] Featherstone, S. "Jams, jellies, and related products. A Complete Course in Canning and Related Processes." Processing Procedures for Canned Food Products 3, (2015): 313-349. https://doi.org/10.1016/B978-0-85709-679-1.00009-X

[19] Khamsucharit, Phaviphu, Kamlai Laohaphatanalert, Paiboolya Gavinlertvatana, Klanarong Sriroth, and Kunruedee Sangseethong. "Characterization of pectin extracted from banana peels of different varieties." Food science and biotechnology 27, no. 3 (2018): 623-629. https://doi.org/10.1007/s10068-017-0302-0

[20] Yuliarti, Oni, Amanda Low Sok Hoon, and Sin Yee Chong. "Influence of pH, pectin and Ca concentration on gelation properties of low-methoxyl pectin extracted from Cyclea barbata Miers." Food Structure 11 (2017): 16-23. https://doi.org/10.1016/j.foostr.2016.10.005

[21] Hussain, Majid, Serafim Bakalis, Ourania Gouseti, Tahir Zahoor, Faqir Muhammad Anjum, and Muhammad Shahid. "Dynamic and shear stress rheological properties of guar galactomannans and its hydrolyzed derivatives." International journal of biological macromolecules 72 (2015): 687-691.

https://doi.org/10.1016/i.ijbiomac.2014.09.019

[22] Benmokhtar, Aissa, and Zakaria Boumerzoug. "Effect of oxygen pressure on the microstructure and mechanical properties of Mo coating deposited on steel 42CD4 by thermal flame spraying." Journal of Adhesion Science and Technology 34, no. 7 (2020): 769-781. https://doi.org/10.1080/01694243.2019.1685742

[23] Zhong, Lirong, Martinus Oostrom, Michael J. Truex, Vincent R. Vermeul, and James E. Szecsody. "Rheological behavior of xanthan gum solution related to shear thinning fluid delivery for subsurface remediation." Journal of hazardous materials 244 (2013): 160-170. https://doi.org/10.1016/i.jhazmat.2012.11.028

[24] Bédié, Gerard K., Sylvie L. Turgeon, and Joseph Makhlouf. "Formation of native whey protein isolate-low methoxyl pectin complexes as a matrix for hydro-soluble food ingredient entrapment in acidic foods." Food Hydrocolloids 22, no. 5 (2008): 836-844.

https://doi.org/10.1016/j.foodhyd.2007.03.010

[25] Salminen, Hanna, and Jochen Weiss. "Effect of pectin type on association and pH stability of whey protein-pectin complexes." Food biophysics 9, no. 1 (2014): 29-38.

https://doi.org/10.1007/s11483-013-9314-3

[26] De Kruif, Cornelus G., Fanny Weinbreck, and Renko de Vries. "Complex coacervation of proteins and anionic polysaccharides." Current opinion in colloid \& interface science 9, no. 5 (2004): 340-349. https://doi.org/10.1016/i.cocis.2004.09.006

[27] Maneerat, Nitjaree, Nattapol Tangsuphoom, and Anadi Nitithamyong. "Effect of extraction condition on properties of pectin from banana peels and its function as fat replacer in salad cream." Journal of food science and technology 54, no. 2 (2017): 386-397.

https://doi.org/10.1007/s13197-016-2475-6

[28] Logan, Kirstyn, Amanda J. Wright, and H. Douglas Goff. "Correlating the structure and in vitro digestion viscosities of different pectin fibers to in vivo human satiety." Food \& function 6, no. 1 (2015): 62-70. https://doi.org/10.1039/C4FO00543K

[29] Marciani, Luca, Penny A. Gowland, Robin C. Spiller, Pretima Manoj, Rachel J. Moore, Paul Young, and Annette J. Fillery-Travis. "Effect of meal viscosity and nutrients on satiety, intragastric dilution, and emptying assessed by MRI." American Journal of Physiology-Gastrointestinal and Liver Physiology 280, no. 6 (2001): G1227-G1233. https://doi.org/10.1152/ajpgi.2001.280.6.G1227

[30] Fontenot, Kevin, and F. Joseph Schork. "Sensitivities of droplet size and stability in monomeric emulsions." Industrial \& engineering chemistry research 32, no. 2 (1993): 373-385. https://doi.org/10.1021/ie00014a014

[31] Padalkar, Abhay N., Sadhana R. Shahi, and M. W. Thube. "Microparticles: an approach for betterment of drug delivery system." Int. J. Pharm. Res. Dev 1 (2011): 99-115.

[32] McClements, D. J., E. A. Decker, and J. Weiss. "Emulsion-based delivery systems for lipophilic bioactive components." Journal of food science 72, no. 8 (2007): R109-R124.

https://doi.org/10.1111/i.1750-3841.2007.00507.x 